Received: 30 July 2018

Accepted: 28 November 2018

Published online: 23 January 2019

NTIFIC REPRTS

\title{
Modifying the transition
}

temperature, $120 \mathrm{~K} \leq \mathrm{T}_{\mathrm{c}} \leq 1150 \mathrm{~K}$,

of amorphous $\mathrm{Fe}_{90-x} \mathrm{Co}_{x} \mathrm{Sc}_{10}$

with simultaneous alteration of
fluctuation of exchange integral up

\section{to zero}

\author{
Y. N. Fang ${ }^{1}$, H. Hahn ${ }^{1,2}$, S. Kobe ${ }^{3}$, R. Witte ${ }^{2}$, S. P. Singh $\mathbb{D}^{2}$, T. Feng ${ }^{1}$ \& M. Ghafari $\mathbb{D}^{1}$
}

Amorphous (a-) $\mathrm{Fe}_{90-\mathrm{x}} \mathrm{Co}_{x} \mathrm{Sc}_{10}$ alloys have been produced by rapid quenching from the melt. The Curie temperature, $T_{C}$, was determined using both mean field theory and Landau's theory of second-order phase transitions in zero and non-zero external fields. The dependence of $\mathrm{T}_{C}$ on the atomic spacing can be explained by the empirical Bethe-Slater curve. The value of $\mathrm{T}_{\mathrm{C}}$ of $\mathrm{a}-\mathrm{Fe}_{5} \mathrm{Co}_{85} \mathrm{Sc}_{10}$, determined by the above theoretical approaches is $1150 \mathrm{~K}$, which is the highest $\mathrm{T}_{C}$ ever measured for amorphous alloys. The flattening of the measured normalized magnetization, $\mathrm{M}(\mathrm{T}) / \mathrm{M}(0)$, as a function of the reduced temperature, $T / T_{C}$, is explained within the framework of the Handrich- Kobe model. According to this model the fluctuation of the exchange integral is the main reason for the flattening of $M(T) / M(0)$. In the case of a- $\mathrm{Fe}_{90} \mathrm{Sc}_{10}$ without $\mathrm{Co}$, however, the fluctuation of the exchange integral is dominant only at zero external field, $B_{e x}=0$. At $B_{e x}=9 T$, however, the fluctuation of the exchange integral has no conspicuous effect on the reduction of the magnetization. It is shown that at $B_{e x}=9 T$ the frozen magnetic clusters control the behaviour of the reduced magnetization as function of $T / T_{C}$. In contrast to other ferromagnetic alloys, where the flattening of $M(T) / M(0)$ is characteristic for an amorphous structure, the a- $\mathrm{Fe}_{5} \mathrm{CO}_{85} \mathrm{Sc}_{10}$ does not exhibit any trace of the fluctuation of the exchange integral.

Efforts have been made to produce soft magnetic materials with high saturation magnetization, high Curie temperature, low magnetic coercivity, high permeability and low magnetostriction. These aims are mostly achieved by Co-based amorphous alloys. These physical properties combined with outstanding soft magnetic properties and high crystallization temperature is of central importance for the application in many technical devices ${ }^{1}$. Currently, it has been reported that a- $\mathrm{Co}_{90} \mathrm{Sc}_{10}$ has a high Curie temperature $(\mathrm{Tc}>860 \mathrm{~K})$ and good soft magnetic properties $^{2}$.

This investigation is based on objectives aimed at producing amorphous alloys with high transition temperature and simultaneous reduction of variations of magnetization curve as a function of temperature to approximately zero in the range $\mathrm{T}=300 \pm 100 \mathrm{~K}$. Additional major goal of this investigation is to study under which conditions the fluctuation of exchange integral becomes extinct. The amorphous transition metal-rich $\mathrm{Fe}_{90-}$ ${ }_{\mathrm{x}} \mathrm{Co}_{\mathrm{x}} \mathrm{Sc}_{10}$ system is one of the means to achieve the above mentioned objective. In addition, the amorphous transition metal-rich $\mathrm{Fe}_{90-\mathrm{x}} \mathrm{Co}_{\mathrm{x}} \mathrm{Sc}_{10}$ system, which exhibits high values of the Curie temperature and the magnetization is of interest in order to study the fundamentals of the dependence of the magnetization on the Co concentration.

${ }^{1}$ Herbert Gleiter Institute of Nanoscience, Nanjing University of Science and Technology, Nanjing, 210094, China. ${ }^{2}$ Institute for Nanotechnology, Karlsruhe Institute of Technology (KIT), Hermann-von-Helmholtz- Platz 1, 76344, Eggenstein- Leopoldshafen, Germany. ${ }^{3}$ Technische Universität Dresden, Institut für Theoretische Physik, D-01062, Dresden, Germany. Correspondence and requests for materials should be addressed to M.G. (email: ghafarijorabi@ gmail.com) 


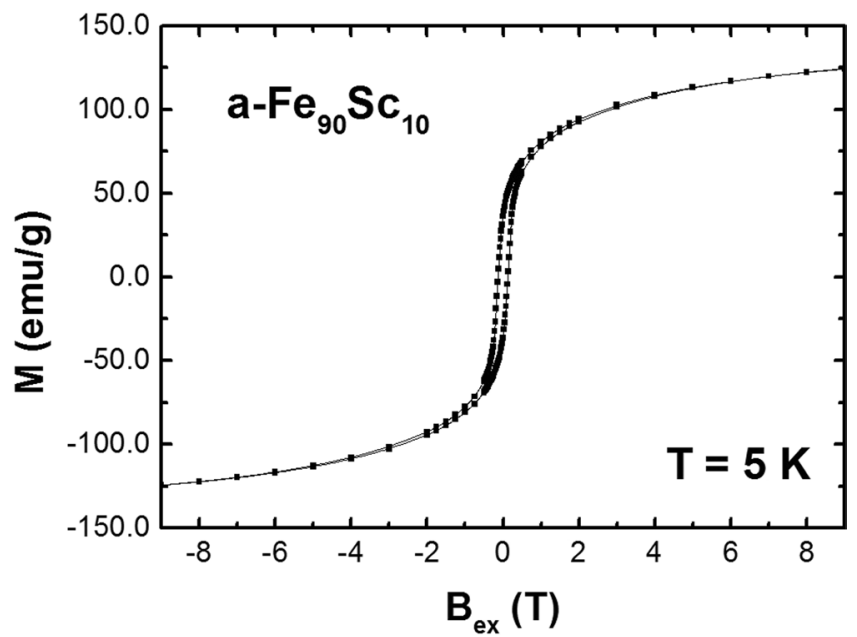

Figure 1. Magnetization of a- $\mathrm{Fe}_{90}-\mathrm{Sc}_{10}$ as a function of $\mathrm{B}_{\mathrm{ex}}$ at $\mathrm{T}=4.2 \mathrm{~K}$. The a- $\mathrm{Fe}_{90}-\mathrm{Sc}_{10}$ is magnetically disordered. The saturation magnetization cannot be achieved even at $\mathrm{B}_{\mathrm{ex}}=9 \mathrm{~T}$ (see text). The magnetic transition is $\mathrm{T}=120 \mathrm{~K}$.

In contrast to a- $\mathrm{Co}_{90} \mathrm{Sc}_{10}$ alloys ${ }^{2}, \mathrm{a}-\mathrm{Fe}_{90} \mathrm{Sc}_{10}$ alloys are magnetically harder with a coercivity of about $\mathrm{H}_{\mathrm{c}} \approx 0.18 \mathrm{~T}$, Fig. 1. The magnetization of a- $\mathrm{Fe}_{90} \mathrm{Sc}_{10}$ at a temperature of $5 \mathrm{~K}$ cannot be saturated even at applied external fields $B_{e x} \geq 8 \mathrm{~T}$, Fig. 1. On the other hand, the magnetic transition temperature $\left(T_{C}=120 \mathrm{~K}\right)$ is extremely reduced in comparison to the amorphous Co based alloys. The physical reason for this abnormal magnetic behaviour of based on frustration of exchange coupling and has been reported in ref. ${ }^{3}$.

Combining the different magnetic behaviour of the two amorphous systems $\mathrm{CoSc}$ and FeSc was the initial idea behind synthesizing amorphous ternary alloys in the CoFeSc system.

\section{Experimental}

Master alloys with the nominal composition of $\mathrm{Fe}_{90-\mathrm{x}} \mathrm{Co}_{\mathrm{x}} \mathrm{Sc}_{10}(0 \leq<\mathrm{x}<\leq 90)$ were synthesized by arc melting in an argon atmosphere. Amorphous $\mathrm{Fe}_{90-\mathrm{x}} \mathrm{Co}_{\mathrm{x}} \mathrm{Sc}_{10}$ ribbons were prepared using melt spinning with a wheel speed of $45 \mathrm{~m} / \mathrm{s}$ in an argon atmosphere. The amorphous ribbons had a thickness of approx. $30 \mu \mathrm{m}$ and a width of approx. $2 \mathrm{~mm}$. Energy Dispersive X-ray Spectroscopy EDX (Oxford Instruments) was used to analyze the composition of the ribbons in comparison to the starting material. X-ray diffraction measurements of a- $\mathrm{Fe}_{90-}$ ${ }_{x} \mathrm{Co}_{\mathrm{x}} \mathrm{Sc}_{10}$ allow to determine the amorphous structure and under certain conditions to determine the atomic structure and the inter-atomic distances, leading to radial distribution functions. A high-flux rotating anode $\mathrm{X}$-ray diffractometer with high-resolution parallel beam optics was employed to confirm the amorphous structure of the ribbon samples. The selected photon wavelength of Mo-radiation was $\lambda_{\mathrm{Mo} \text {-Ko1 }}=0.7107 \AA$. The conversion of the X-ray diffraction data of a- $\mathrm{Fe}_{90-\mathrm{x}} \mathrm{Co}_{\mathrm{x}} \mathrm{Sc}_{10}$ to atomic Pair Distribution Function, PDF, was made using the PDFgetX3 software ${ }^{4}$. To proof the reliability of this method, the PDF of two representative samples (a- $\mathrm{Fe}_{90} \mathrm{Sc}_{10}$ and $\mathrm{a}-\mathrm{Co}_{90} \mathrm{Sc}_{10}$ ) measured and evaluated ${ }^{2,5}$ at a synchrotron source (Spring-8) with a substantially smaller photon wavelength of $0.2 \AA$ was compared with those obtained by the method described above. It could be confirmed that the data measured using the laboratory instrument coincide well with those measured at the synchrotron, enabling the use of Mo-source instrument with better accessibility. The PDF of a representative sample, a- $\mathrm{Fe}_{45} \mathrm{Co}_{45} \mathrm{Sc}_{10}$, is shown in Fig. 2. It is evident that the atomic structure of the ternary amorphous alloy is similar to that of $\mathrm{a}-\mathrm{Fe}_{90} \mathrm{Sc}_{10}$ or a- $\mathrm{Co}_{90} \mathrm{Sc}_{10}$ both reported earlier to exhibit a distorted bcc structure ${ }^{6}$. It was shown that the distorted bcc structure describes also the atomic structure of other compositions $\mathrm{x}$ over the entire compositional range ${ }^{6}$. In contrast to the crystalline $\mathrm{Fe}_{100-\mathrm{x}} \mathrm{Co}_{\mathrm{X}}$ alloys ${ }^{7}, \mathrm{a}-\mathrm{Fe}_{90-\mathrm{x}} \mathrm{Co}_{\mathrm{x}} \mathrm{Sc}_{10}$ alloys show no structural changes as a function of composition of Co. It is important to note that the partial distribution functions allow to access information such as the distribution and positions of nearest neighbours and thus provide a base for the discussion of magnetic behaviour of a- $\mathrm{Fe}_{90-\mathrm{x}} \mathrm{Co}_{\mathrm{x}} \mathrm{Sc}_{10}$ alloys.

The magnetic studies were performed using SQUID- Quantum Design as well as a Physical Property measurement System $\left(\mathrm{PPMS}^{\circledR}\right.$ )- Quantum Design in temperature range $4.2 \mathrm{~K} \leq \mathrm{T} \leq 1000 \mathrm{~K}$ with external magnetic fields $0<\mathrm{B}_{\mathrm{ex}} \leq 9 \mathrm{~T}$.

For discussion regarding the magnetic behaviour as a function of temperature, it is important that magnetic saturation is achieved. In the case of a- $\mathrm{Fe}_{90} \mathrm{Sc}_{10}$, it is, however, difficult to align the spin in external fields directions. The detail information for this behaviour is given in ref. ${ }^{3}$. The internal magnetic hyperfine field splitting, $\mathrm{B}_{\mathrm{hf}}$, is in the most transition metal based alloys proportional to the magnetic moment of $\mathrm{Fe}^{8}$. Fortunately, the $\mathrm{B}_{\mathrm{hf}}$ is unrestricted to the orientation of spins and it is assessable by nuclear methods such as Mössbauer spectroscopy. As with most transition metals ${ }^{8}$, assuming that the following equation, $\mathrm{M}(\mathrm{T}) / \mathrm{M}(0)=\mathrm{B}_{\mathrm{hf}}(\mathrm{T}) / \mathrm{B}_{\mathrm{hf}}(0)$, is authentic between the magnetization and average magnetic hyperfine field, the magnetic behaviour as a function of temperature of a- $\mathrm{Fe}_{90} \mathrm{Sc}_{10}$ will be discussed in this report. The details of the evaluation of $\mathrm{B}_{\mathrm{hf}}(\mathrm{T})$ have been discussed in ref. ${ }^{9}$. 


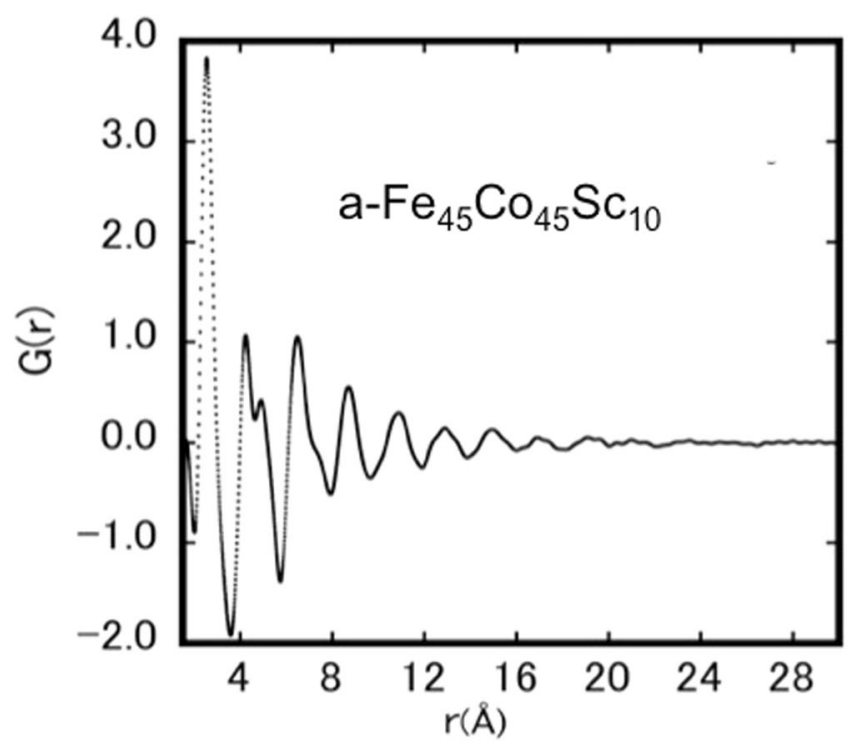

Figure 2. A representative Pair Distribution Functions, $\mathrm{G}(\mathrm{r})$, of $\mathrm{a}-\mathrm{Fe}_{90-\mathrm{x}} \mathrm{Co}_{\mathrm{x}} \mathrm{Sc}_{10}$ at room temperature.

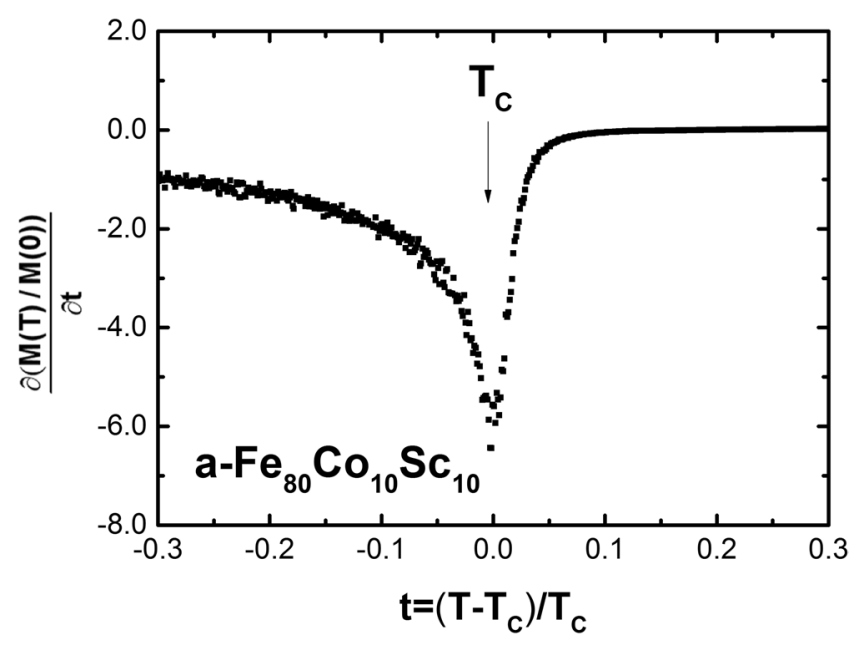

Figure 3. A representative plot of the slope of $M(T) / M(0)$ as a function of normalized temperature $t=\left(T-T_{C}\right) /$ $\mathrm{T}_{\mathrm{C}}$ is presented. According to Landau theory is the Curie temperature at the point of inflection, $\mathrm{t}=0$ (See text).

For $\mathrm{x}>0$, the Curie temperatures of a- $\mathrm{Fe}_{90-\mathrm{x}} \mathrm{Co}_{\mathrm{x}} \mathrm{Sc}_{10}$ were verified through two different methods: (1) for $\mathrm{x} \leq 35, \mathrm{~T}_{\mathrm{C}}$ was deduced by mean of Landau theory ${ }^{10}$. (2) For $\mathrm{x}>35$, the mean field theory were applied to calculated the $\mathrm{T}_{C}$. The reason for the choice of two different methods is the crystallization of samples. At $\mathrm{x}>35$, the $\mathrm{T}_{\mathrm{C}}$ is higher than the crystallization temperature and the Landau theory cannot be applied ${ }^{10}$.

In general, $\mathrm{T}_{\mathrm{C}}$ is a second order phase transition from magnetically random disordered state to a magnetically well-ordered state. According to Landau ${ }^{10}$ the fourth-order expansion of free minimum energy in an external field or in zero external field at $\mathrm{T}_{\mathrm{C}}$ delivers a point of inflection for the slope of $\mathrm{M}(\mathrm{T}) / \mathrm{M}(0)$ at $\mathrm{t}=\left(\mathrm{T}-\mathrm{T}_{\mathrm{C}}\right) / \mathrm{T}_{\mathrm{C}}=0$.

A representative figure of the slope, $\partial \mathrm{M}(\mathrm{T}) / \partial \mathrm{M}(0)$, as a function of $\mathrm{t}=\left(\mathrm{T}-\mathrm{T}_{\mathrm{C}}\right) / \mathrm{T}_{\mathrm{C}}$ is presented in Fig. 3 .

At $\mathrm{x}>35, \mathrm{~T}_{\mathrm{C}}$ is above crystallization temperature $\mathrm{T}_{\mathrm{X}}$. For determination of $\mathrm{T}_{\mathrm{C}}$, the measured magnetization in the range, $90>\mathrm{x}>35$, and at $\mathrm{T}<\mathrm{T}_{\mathrm{c}}$ were satisfactorily matched to the mean field theory equation:

$$
\frac{\mathrm{M}(\mathrm{T})}{\mathrm{M}(0)}=\tanh \left[\frac{\mathrm{M}(\mathrm{T}) / \mathrm{M}(0)}{\mathrm{T} / \mathrm{T}_{\mathrm{C}}}\right]
$$

The results will be discussed in the next section.

The determination of the crystallization temperature, $\mathrm{T}_{\mathrm{X}}$ of a- $\mathrm{Fe}_{90-\mathrm{X}} \mathrm{Co}_{\mathrm{X}} \mathrm{Sc}_{10}$ were performed with a Differential Scanning Calorimetry, NETZSCH STA 449F3 at a heating rate of $20 \mathrm{~K} / \mathrm{min}$, Fig. 4 . 


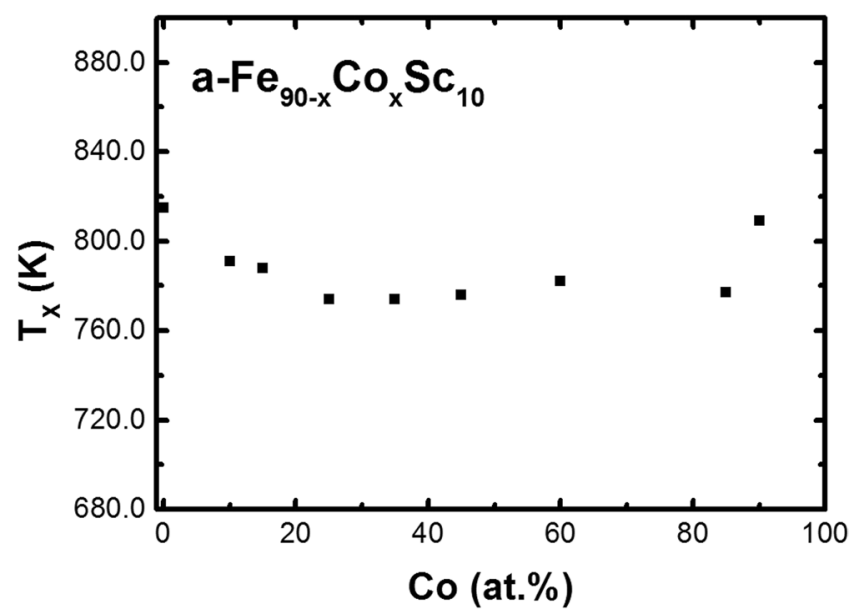

Figure 4. Crystallization temperature as a function of Co.

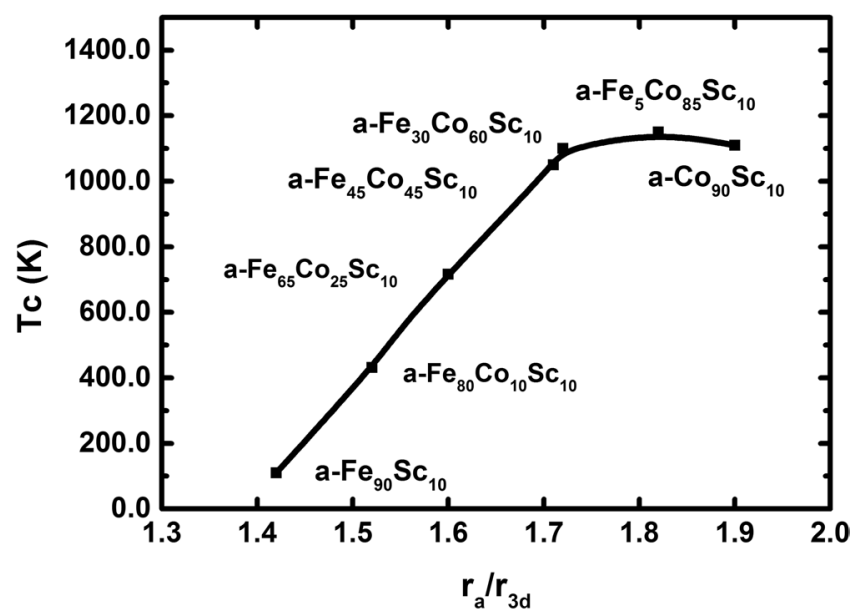

Figure 5. Curie temperature as a function of the ratio of $r_{a} / r_{3 d} \cdot r_{a}$ and $r_{3 d}$ are denoted as the first maximum at PDF-curve and $3 \mathrm{~d}$ radii respectively.

\section{Results and Discussions}

Curie temperature. FeCo-based amorphous alloys have among all transition metals based ferromagnetic amorphous alloys the highest Curie temperature ${ }^{2}$.

The highest Curie temperature is, however, low in comparison to the pure crystalline transition metals. The reasons for this behaviour are: (a) Different arrangements of short-range order in comparison to the crystalline counter part. (2) Alloying effect (3) Distribution of the interatomic distances (4) Different electron structure ${ }^{11}$. Recently, it has been reported that $\mathrm{a}-\mathrm{Co}_{90} \mathrm{Sc}_{10}{ }^{2}$ has the highest $\mathrm{T}_{\mathrm{C}} \approx 1000 \mathrm{~K}$ among the amorphous transition metals. One reason for this high $\mathrm{T}_{\mathrm{C}}$ is the structure of this alloy ${ }^{6}$. Amorphous Transition-metal rich Sc alloys have a distorted bcc structure ${ }^{6}$. According to the experimental Slater- Pauling curve ${ }^{12,13}$, the ratio of $\mathrm{r}_{\mathrm{a}} / \mathrm{r}_{3 \mathrm{~d}}$ determine the exchange integral and with that the $\mathrm{T}_{\mathrm{C}} \cdot \mathrm{r}_{\mathrm{a}}$ and $\mathrm{r}_{3 \mathrm{~d}}$ are denoted as atom diameters and $3 \mathrm{~d}$ shell radii, respectively. Hence, it should be possible to increase the $\mathrm{T}_{\mathrm{c}}$ toward higher values by altering the ratio $\mathrm{r}_{\mathrm{a}} / \mathrm{r}_{3 \mathrm{~d}}$. For this purpose, Fe replaced the Co atoms in the amorphous $\mathrm{Co}_{90} \mathrm{Sc}_{10}$ alloy. The resulting increase of $\mathrm{T}_{c}$ is shown in Fig. 5. The atomic diameter, $r_{a}$, is selected from the first maximum of PDF curve. The resulting curve follows the experimental Slater-Pauling curve. Contrary to the crystalline $\mathrm{Fe}_{100-\mathrm{x}} \mathrm{Co}_{\mathrm{x}}$, there are no structural transitions in a- $\mathrm{Fe}_{90-\mathrm{x}} \mathrm{Co}_{\mathrm{x}} \mathrm{Sc}_{10}$. The shape of the resulting PDF is similar for all a- $\mathrm{Fe}_{90-\mathrm{x}} \mathrm{Co}_{\mathrm{x}} \mathrm{Sc}_{10}$. The main variation is the atomic distances. Using the experimental idea of Slater-Pauling ${ }^{12,13}$, it was possible to reach a $T_{C}$ at $1150 \mathrm{~K}$. This finding is of special interest for the use of soft magnetic properties.

Magnetization. Amorphous samples, a- $\mathrm{Fe}_{5} \mathrm{Co}_{85} \mathrm{Sc}_{10}$, are magnetically soft with a corresponding magnetic moment of the transition metals ( $\mathrm{Fe}$ and $\mathrm{Co}$ ) of about $1.4 \mu_{\mathrm{B}}$ at a temperature of $300 \mathrm{~K}$, as seen in Fig. 6. Replacing just $5 \%$ of the Co-atoms by Fe results in an increase of the Curie temperature to $1150 \mathrm{~K}$ for a- $\mathrm{Fe}_{5} \mathrm{Co}_{85} \mathrm{Sc}_{10}$, which is, to the best of our knowledge, the highest $\mathrm{T}_{\mathrm{C}}$ ever obtained for any amorphous alloys. Furthermore, the magnetic moment of a- $\mathrm{Fe}_{5} \mathrm{Co}_{85} \mathrm{Sc}_{10}$ is higher than a- $\mathrm{Co}_{90} \mathrm{Sc}_{10}$. 


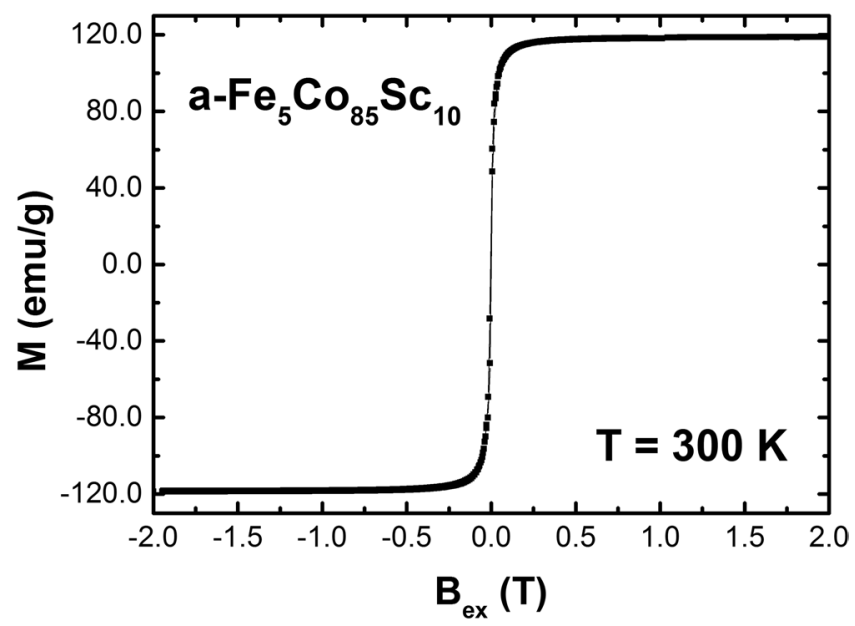

Figure 6. Magnetization as a function of external fields of $\mathrm{a}-\mathrm{Fe}_{85} \mathrm{Co}_{5} \mathrm{Sc}_{10}$ at $\mathrm{T}=300 \mathrm{~K}$.

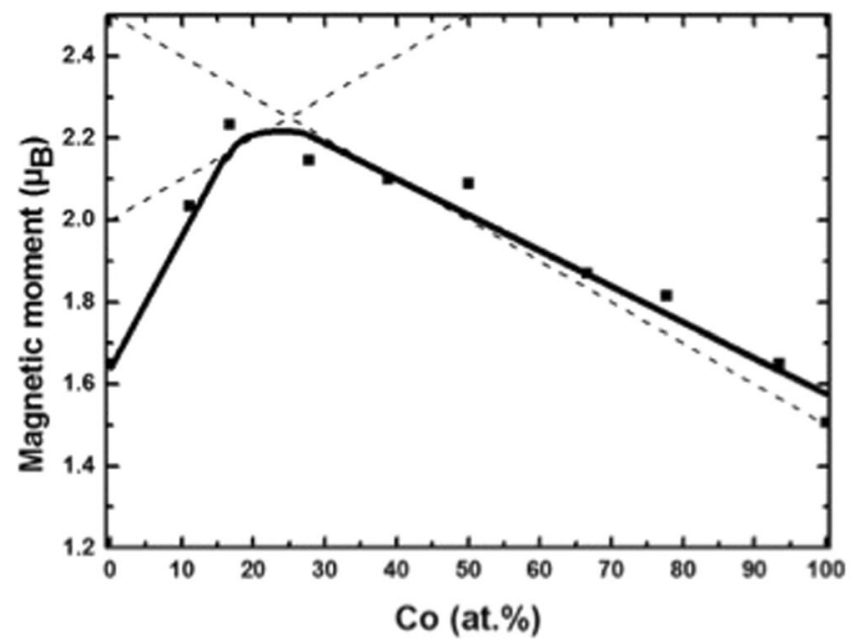

Figure 7. Magnetic moment as a function of Cobalt measured at $4.2 \mathrm{~K}$. The straight dashed lines present calculated values (See text).

Magnetization curve. As mentioned, a- $\mathrm{Fe}_{90-\mathrm{x}} \mathrm{Co}_{\mathrm{x}} \mathrm{Sc}_{10}$ has a distorted bcc structure. The experimental observed magnetic moment as a function of the Co content at $4.2 \mathrm{~K}$ is presented in Fig. 7. A maximum of magnetic moment is indicated at about $\mathrm{x}=25$. The behaviour of $\mathrm{M}(\mathrm{T})$ as a function of Co contents is similar to one reported for the crystalline bcc Fe-Co alloys. Using self- consistent local spin-density functional calculation, Schwarz et al. ${ }^{14}$ have shown that in the case of bcc FeCo alloys are the itinerant $3 \mathrm{~d}$-electrons band with $3 \mathrm{~d}$ spin up as well as $3 \mathrm{~d}$ spin down intensely concentrated close to $\mathrm{Co}$ and $\mathrm{Fe}$ atoms. There is, however, a minor negative contribution of about $-0.02 \mu_{\mathrm{B}}$ between atoms. This contribution is due to the p-electrons. The resulting of Magnetic Compton X-ray Scattering ${ }^{2,15}$ shows, however, a negative value of about $-0.23 \mu_{\mathrm{B}}$ and $-0.49 \mu_{\mathrm{B}}$ for $\mathrm{a}-\mathrm{Co}_{90} \mathrm{Sc}_{10}$ and bcc-Fe, respectively. Similar to crystalline $\mathrm{Fe}_{1-\mathrm{x}} \mathrm{Co}_{\mathrm{X}}$ alloys, the shape of magnetization curve of a- $\mathrm{Fe}_{90-\mathrm{x}} \mathrm{Co}_{\mathrm{x}} \mathrm{Sc}_{10}$ consists of two physical different appearances ${ }^{14}$ : (1) At $100<\mathrm{x}<25$, the spin up electrons are filled. An increase of Fe causes a decrease of spin down and with that an increase of the magnetic moment as appeared in Fig. $5^{14,16}$. Using the equation suggested by Schwarz et al. ${ }^{11,16,17}: \mathrm{M}=2 \mathrm{~N}-\mathrm{Z}$ with $\mathrm{N}=5.22$ was an agreement reached. The values, $\mathrm{M}, \mathrm{N}$ and $\mathrm{Z}$ are defined as magnetic moment, average number of spins and number of valence electrons per atom, respectively. The value of $\mathrm{N}$ is slightly smaller than that chosen for bcc $\mathrm{Fe}^{14}$, Fig. 7. For $\mathrm{x}<25$, an agreement cannot be achieved satisfactorily between theory and experiment, because the Fe atoms are in a- $\mathrm{Fe}_{90} \mathrm{Sc}_{10}$ magnetically disordered. They experience positive, ferromagnetic, as well, negative antiferromagnetic interactions ${ }^{3}$.

(2) At $\mathrm{x}>25$, the spin downs are pinned ${ }^{14}$ and a decrease of Fe leads to an increase of magnetic moment according to the equation: $\mathrm{M}=\mathrm{Z}-2 \mathrm{~N}$. Choosing a value: $\mathrm{N}=3.125$ lead to good agreement between experimental data and the suggested equation as presented in Fig. 7. The selected $\mathrm{N}$ is in comparison to bcc-Fe higher. This could be originated in additional filling of spin down band structure by Sc atoms. 


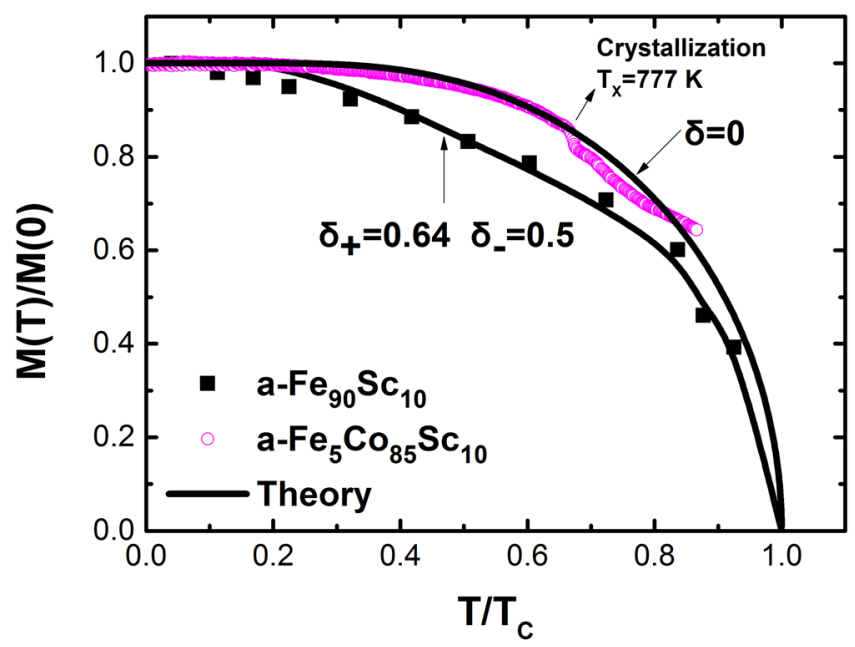

Figure 8. Reduced magnetization $\mathrm{M}(\mathrm{T}) / \mathrm{M}(0)$ as a function of reduced temperature $\mathrm{T} / \mathrm{T}_{\mathrm{C}}$ for two representative samples. The curves are fitted with asymmetric exchange integral fluctuation according to ref. ${ }^{22}$.

Reduced Magnetization: $\mathrm{M}(\mathrm{T}) / \mathrm{M}(0)$. The reduced saturation magnetization, $\mathrm{M}(\mathrm{T}) / \mathrm{M}(0)$, of a- $\mathrm{Co}_{85} \mathrm{Fe}_{5} \mathrm{Sc}_{10}$ as a function of reduced temperature, $\mathrm{T} / \mathrm{Tc}$, measured from $4.2 \mathrm{~K}$ up to the crystallization temperature, $\mathrm{T}_{\mathrm{X}}=777 \mathrm{~K}$, agrees with the prediction of the mean field theory, Fig. 8 . This behavior is comparable to crystalline materials. In contrast to other distorted systems such as amorphous alloys no modification of the Brillouin function was necessary to calculate the experimental data. The best agreement of the theoretical description with the experimental data is achieved by using an extrapolated Curie temperature, $T_{C}=1150 \mathrm{~K}$. As crystallization of the amorphous structure sets in prior to reaching the Curie temperature, the transition temperature cannot be determined experimentally. The same calculation of the Curie temperature has been employed to determine $\mathrm{T}_{\mathrm{C}}$ for crystalline $\mathrm{Fe}, \mathrm{Co}$ and $\mathrm{Ni}^{18}$.

According to Handrich and Kobe, the mean field theory predicts successfully the temperature dependence of the reduced saturation magnetization, $\mathrm{M}(\mathrm{T}) / \mathrm{M}(0)$, if the Brillouin function is modified ${ }^{19-21}$. The modified Brillouin function takes into account the effect of the distorted structure and the variation of interatomic spacing between nearest neighbors on exchange integral. In Handrich and Kobe theory ${ }^{19-21}$, the reduced saturation magnetization is given by:

$$
\frac{\mathrm{M}(\mathrm{T})}{\mathrm{M}(0)}=\frac{1}{2}\left\{\mathrm{~B}_{\mathrm{s}}[(1+\delta) \mathrm{x}]+\mathrm{B}_{\mathrm{s}}[(1-\delta) \mathrm{x}]\right\}
$$

$\mathrm{x}$ and $\delta$ are defined as:

$$
\mathrm{x}=\frac{3 \mathrm{~S}}{\mathrm{~S}+1} \frac{\mathrm{M}(\mathrm{T})}{\mathrm{M}(0)} \frac{\mathrm{T}_{\mathrm{C}}}{\mathrm{T}}, \quad \delta=\sqrt{\left\langle\Delta J^{2}\right\rangle /\langle\mathrm{J}\rangle^{2}}
$$

The parameters $B_{s}, J$ and $\Delta J$ are defined as the Brillouin function, exchange integral and exchange fluctuation, respectively.

According to Gallagher et al..$^{22}$, the Handrich- Kobe model would be improved, if the asymmetric exchange fluctuations were included. The asymmetrical distribution of the exchange integral is the result of the form of the empirical Bethe-Slater curve, which permits the replacement of $\delta$ parameters in equation (2) by two different parameters, $\delta_{+}$and $\delta_{-}$. The alternative equation is expressed as:

$$
\frac{\mathrm{M}(\mathrm{T})}{\mathrm{M}(0)}=\frac{1}{2}\left\{\mathrm{~B}_{\mathrm{s}}\left[\left(1+\delta_{+}\right) \mathrm{x}\right]+\mathrm{B}_{\mathrm{s}}\left[\left(1-\delta_{-}\right) \mathrm{x}\right]\right\}
$$

Using the method of Gallagher et al. ${ }^{22}$ a zero exchange fluctuation parameter, $\delta=\sqrt{ }(\Delta \mathrm{J} 2) /(\mathrm{J})^{2}=0$, was deduced for a- $\mathrm{Fe}_{5} \mathrm{Co}_{85} \mathrm{Sc}_{10}$. The best agreement between the theory, equation 3 , and measurements of a-Fe $\mathrm{Se}_{90} \mathrm{Sc}_{10}$ was reached by an asymmetric exchange fluctuation parameters, $\delta+=0.64$ and $\delta-=0.5$, Fig. 8 . In the case of a- $\mathrm{Fe}_{90} \mathrm{Sc}_{10}$ the saturation magnetization cannot be reached in external fields. Therefore for the determination of $\mathrm{M}(\mathrm{T}) / \mathrm{M}(0)$, we must move away from the standard ways such as SQUID- or PPMS measurements. Mössbauer effect is an alternative method for the determination of $\mathrm{M}(\mathrm{T}) / \mathrm{M}(0)$. As discussed in section 2 , the measured average magnetic hyperfine field, $\mathrm{B}_{\mathrm{hf}}(\mathrm{T})$, at zero external magnetic field is in transition metals proportional to the $M(T)$. Therefore for the calculation of $M(T) / M(0)$, the equation: $B_{h f}(T) / B_{h f}(0)=M(T) / M(0)$ has been used. It is worth remembering that the $\mathrm{a}-\mathrm{Fe}_{90} \mathrm{Sc}_{10}$ consists of magnetic clusters with an average sizes of about 100 atoms. The measured $\mathrm{B}_{\mathrm{hf}}(\mathrm{T}) / \mathrm{B}_{\mathrm{hf}}(0)=\mathrm{M}(\mathrm{T}) / \mathrm{M}(0)$ is within clusters.

In the next section, it will be shown that for a- $\mathrm{Fe}_{90} \mathrm{Sc}_{10}$, the exchange fluctuation parameter in an applied magnetic field of $9 \mathrm{~T}$ can be depressed to zero. In this case the magnetic movement of whole single cluster and their 

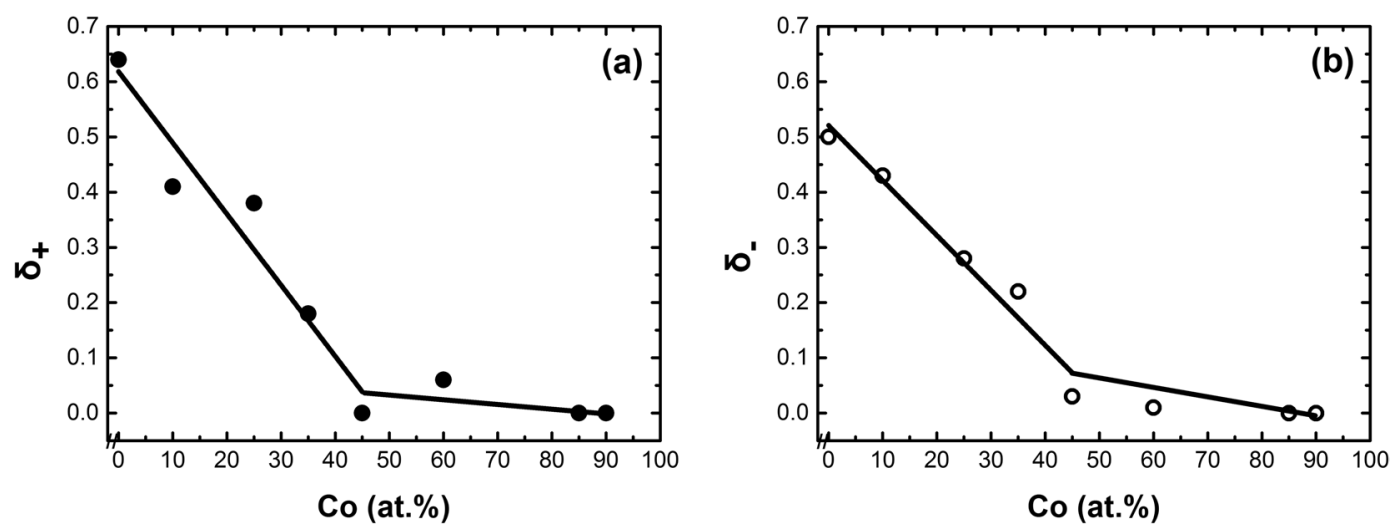

Figure 9. (a,b) Asymmetric exchange integral fluctuations, $\delta_{+}$and $\delta_{-}$, as a function of Cobalt. $\delta_{+}$and $\delta_{-}$were determined from the best agreement between theory and experiment (see text).

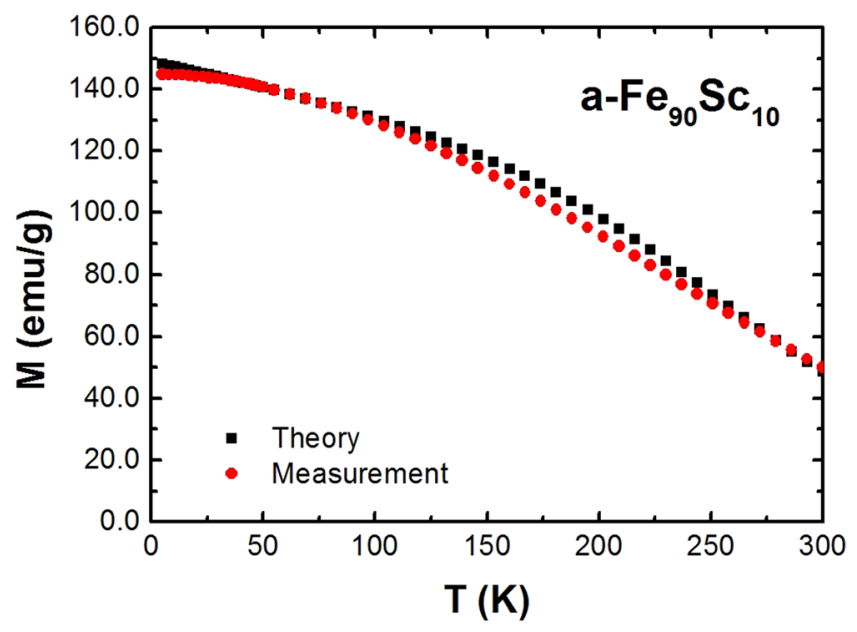

Figure 10. Measured and calculated magnetization as a function temperature of a-Fe $\mathrm{Sc}_{10}$ measured at $\mathrm{B}_{\mathrm{ex}}=9 \mathrm{~T}($ see text $)$.

interaction with other clusters are decisive for the behavior of $\mathrm{M}(\mathrm{T})$. The individual spins in the cluster do not play an essential role. This uncommon effect is of special interest and will be discussed in details.

The $\mathrm{M}(\mathrm{T}) / \mathrm{M}(0)$ curve of ferromagnetic amorphous alloys as a function of $\mathrm{T} / \mathrm{T}_{\mathrm{C}}$ are in contrast to the comparable crystalline alloys flatter. The mean field theory seems unable to explain the behaviour of magnetization as a function of temperature. However, by considering the distorted short-range order of atoms, Handrich and Kobe $^{19,20}$ were able to explain the magnetization behaviour as function of temperature in the context of a modified mean field theory. A meaningful improvement on the theory of Handrich and Kobe were reached by considering the asymmetric exchange fluctuation of exchange integral according to Bethe-Slater curves. Using equation 4 in ref. $^{22}$, the measured $\mathrm{M}(\mathrm{T}) / \mathrm{M}(0)$, or average magnetic hyperfine field $\mathrm{B}_{\mathrm{hf}}(\mathrm{T}) / \mathrm{B}_{\mathrm{hf}}(0)$, were matched to the theory. The results for two representative samples are presented in Fig. 8.

The two asymmetric parameters, $. \delta_{+} . \delta_{-}$of a- $\mathrm{Fe}_{90-\mathrm{x}} \mathrm{Co}_{\mathrm{x}} \mathrm{Sc}_{10}$ are presented in Fig. 9. The two asymmetric parameters are in a comparative agreement to the Bethe-Slater curve. Above $\mathrm{x}>25$, a variation of exchange integral is rather small; therefore the $\delta_{+}$and $\delta$ tend to be low as presented in Fig. 9.

$\mathrm{M}(\mathrm{T}) / \mathrm{M}(0)$ of a- $\mathrm{Fe}_{90} \mathrm{Sc}_{10} . \quad$ a- $\mathrm{Fe}_{90} \mathrm{Sc}_{10}$ is an exception: This amorphous alloy consists of ferro- and antiferromagnetic couplings. In addition, this alloy is made up of separated magnetic clusters with an average size of about 10 to $12 \AA^{3}$ with a transition temperature at $120 \mathrm{~K}$ in zero field ${ }^{3}$. At $\mathrm{T}<120 \mathrm{~K}$, the spins have inside the clusters a mixed coupling (ferro- and antiferromagnetic). The resulting reduced magnetization $\mathrm{M}(\mathrm{T}) / \mathrm{M}(0)$ as a function of $\mathrm{T} / \mathrm{T}_{\mathrm{C}}$ inside the clusters can be described with the modified Brillouin function according to Handrich and Kobe theory. The outcome of the calculation and the measurements inside the clusters are presented in Fig. 8.

A totally different outcome was registered in the temperature dependence of $\mathrm{M}(\mathrm{T}) / \mathrm{M}(0)$ at external magnetic field, $B_{\mathrm{ex}}=9 \mathrm{~T}$.

In a- $\mathrm{Fe}_{90} \mathrm{Sc}_{10}$, the magnetic clusters are relative to each other randomly distributed and there is no magnetic interaction between them. In other words, the clusters behaviour to each other likes individual atoms in paramagnetic state. Using an average magnetic moment of $100 \mu_{\mathrm{B}}$ for every cluster, a good agreement between experiment 
and mean field theory of paramagnet can be achieved. In this case the exchange fluctuations have no influence on $\mathrm{M}(\mathrm{T}) / \mathrm{M}(0)$ of clusters. The results are presented in Fig. 10.

\section{Conclusions}

Amorphous $\mathrm{Fe}_{90-\mathrm{x}} \mathrm{Co}_{\mathrm{x}} \mathrm{Sc}_{10}$ alloys have been prepared by rapidly quenching the melt. The short range order, the magnetic moment, the Curie temperature and the temperature dependence of magnetization have been investigated in detail. The results obtained for amorphous transition rich-Sc alloys agree with the prediction of modified mean field theory. The amorphous $\mathrm{Fe}_{5} \mathrm{Co}_{85} \mathrm{Sc}_{10}$ alloys follow up to crystallization theory the exact mean field theory without any modification. Above $\mathrm{x}>35 \mathrm{~K}$, the magnetic moment can be explained satisfactorily with the theoretical band model of bcc structure. The calculated $\mathrm{T}_{\mathrm{C}}$ of $1150 \mathrm{~K}$ of a- $\mathrm{Fe}_{5} \mathrm{Co}_{85} \mathrm{Sc}_{10}$ is the highest $\mathrm{T}_{\mathrm{C}}$ reported so far for amorphous alloys. The exceptional magnetic character of an amorphous $\mathrm{Fe}_{90} \mathrm{Sc}_{10}$ alloy is discussed in the framework of magnetic clusters with distorted bcc structure.

Hence we are led to conclude that the high Curie temperature is related to the bcc ordering in these alloys.

\section{References}

1. Herzer, G. Amorphous and nanocrystalline soft magnets. Magnetic Hysteresis In Novel Magnetic Material 338, 711-730 (1997).

2. Ghafari, M. et al. Unexpected magnetic behavior in amorphous $\mathrm{Co}_{90} \mathrm{Sc}_{10}$ alloy. Appl. Phys. Lett. 107, 132406-1- 132406-4 (2015).

3. Ghafari, M., Day, R. K., Dunlop, J. B. \& McGrath, A. C. Spin coupling in amorphous $\mathrm{F}_{\mathrm{e} 9} 0 \mathrm{~S}_{\mathrm{c} 1} 0$ alloy. J. Magn. Magn. Mater. 104-107, $1668-1670$ (1992).

4. Juhás, P., Davis, T., Farrow, C. L. \& Billinge, S. J. L. PDFgetX3: A rapid and highly automatable program for processing powder diffraction data into total scattering pair distribution functions. J. Appl. Crystallogr. 46, 560-566 (2013).

5. Ghafari, M., Kohara, S., Hahn, H. \& Gleiter, H. Structural investigations of interfaces in $\mathrm{Fe}_{90} \mathrm{Sc}_{10}$ nanoglasses using high-energy $\mathrm{x}$-ray diffraction. Appl. Phys. Lett. 100, 133111-1-133111-4 (2012).

6. Ghafari, M., Gleiter, H., Feng, T. K. O. \& Hahn, H. Are Transition Metal-Rich Metallic Glasses Made Up of Distorted BCC Clusters? J. Material Sci. Eng. 5, 1000299-1-1000299-4 (2016).

7. Hamdeh, H. H., Fultz, B. \& Pearson, D. H. Mössbauer spectrometry study of the hyperfine fields and electronic structure of Fe-Co alloys. Phys. Rev. B39, 11233-11240 (1989).

8. Marshall, W. \& Johnson, C. E. Hyperfine field in metals and alloys. J. Phys. Radium 23, 733-737 (1962).

9. Day, R. K., Dunlop, J. B., Foley, C. P., Ghafari, M. \& Pask, H. Preparation and Mössbauer study of a new Fe-rich amorphous alloy, $\mathrm{Fe}_{90} \mathrm{Sc}_{10}$. Solid State Commun. 56, 843-845 (1985).

10. Landau, L. D. \& Lifshitz, E. M. Statistical Physics, 3rd Edition. Course of Theoretical Physics Vol. 5, 447-510 (Pergamon Press, Oxford, 1980).

11. Ghafari, M. et al. Electrical resistivity and wave character of free electrons in amorphous and nanoglass $\mathrm{Sc}_{75} \mathrm{Fe}_{25}$. J. Phys. Condens. Matter. 30, 025702 (6pp) (2018).

12. Slater, J. C. Electronic Structure of Alloys. J. Appl. Phys. 8, 385-390 (1937).

13. Pauling, L. The Nature of the Interatomic Forces inMetals. Phys. Rev. 54, 899-904 (1938).

14. Schwarz, K., Mohn, P., Blaha, P. \& Kübler, J. Electronic and magnetic structure of BCC Fe-Co alloys from band theory. J. Phys. F: Met. Phys. 14, 2659-2671 (1984).

15. Ghafari, M. et al. Evidence of itinerant magnetism in a metallic nanoglass. Appl. Phys. Lett. 101, 243104-1-243104-4 (2012).

16. Berger, L. Electronic Specific Heat and Saturation Magnetization of Cr-Fe and Fe-Co Alloys. Phys. Rev. 137, A220-A227 (1965).

17. Malozemoff, A. P., Williams, A. R. \& Moruzzi, V. L. "Band-gap theory" of strong ferromagnetism: Application to concentrated crystalline and amorphous Fe- and Co-metalloid alloys. Phys. Rev. B 29, 1620-1632 (1984).

18. Cullity, B. \& Graham, C. Introduction to Magnetic Materials P. 117-130. (John Wiley \& Sons, Inc., Hoboken, New Jersey, 2009).

19. Handrich, K. A Simple Model for Amorphous and Liquid Ferromagnets. Phys. Status Solidi 32, K55 (1969).

20. Handrich, K. \& Kobe, S. Theory of amorphous and liquid ferromagnets. Acta Phys. Pol. A38, 819-824 (1970).

21. Kobe, S. \& Handrich, K. Influence of structure fluctuation on magnetic properties of an amorphous ferromagnet. Sov. Phys. Sol. State 13, 734-736 (1971).

22. Gallagher, K. A., Willard, M. A., Zabenkin, V. N., Laughlin, D. E. \& Mchenry, M. E. Distributed exchange interactions and temperature dependent magnetization in amorphous $\mathrm{Fe}_{88-\mathrm{x}} \mathrm{Co}_{\mathrm{x}} \mathrm{Zr}_{7} \mathrm{~B}_{4} \mathrm{Cu}_{1}$ alloys. J. Appl. Phys. 85, 5130-5132 (1999).

\section{Acknowledgements}

We would like to express our thank to Dr. Juhas, his co-authors and Columbia university for allowing MG to use the PDFgetX3-Program for the scientific investigations (License Agreement \#7124-columbia).

\section{Author Contributions}

M.G. introduced the idea of this study. M.G. and S.K. used the computational techniques and theory for interpretation of magnetization results. M.G. did the analysis of X-ray measurements. Y.N.F. prepared the samples. M.G. measured and analyzed the Mößbauer data. Y.N.F assisted M.G. to perform calculations. Y.N.F. did calorimetric and a part of magnetization measurements. R.W. and S.S. did SQUID- and a part of PPMS measurements. M.G. and H.H. wrote the manuscript. M.G., S.K. and H.H. interpreted the results. T.F. supervised the Y.N.F. work.

\section{Additional Information}

Competing Interests: Dr. Juhas, his co-authors and Columbia university named on manuscript allow M.G. to use the PDFgetX3-Program for the scientific investigations (License Agreement \#7124-columbia). The remaining authors have no competing interests.

Publisher's note: Springer Nature remains neutral with regard to jurisdictional claims in published maps and institutional affiliations. 
(i) Open Access This article is licensed under a Creative Commons Attribution 4.0 International License, which permits use, sharing, adaptation, distribution and reproduction in any medium or format, as long as you give appropriate credit to the original author(s) and the source, provide a link to the Creative Commons license, and indicate if changes were made. The images or other third party material in this article are included in the article's Creative Commons license, unless indicated otherwise in a credit line to the material. If material is not included in the article's Creative Commons license and your intended use is not permitted by statutory regulation or exceeds the permitted use, you will need to obtain permission directly from the copyright holder. To view a copy of this license, visit http://creativecommons.org/licenses/by/4.0/.

(C) The Author(s) 2019 